\title{
Exploring the rainfall data from satellites to monitor rainfall induced landslides - A case study
}

\author{
Manoj Kumar Thakur ${ }^{1,2}$, Srinivas Desamsetti ${ }^{3}$, A. Naga Rajesh $^{1}$, Koteswara Rao. K ${ }^{4}$, M.S. \\ Narayanan $^{1}$, T.V. Lakshmi Kumar ${ }^{1^{*}}$ \\ ${ }^{1}$ Atmospheric Science Research Laboratory, Department of Physics, \\ SRM Institute of Science and Technology, Kattankulathur,603203, India \\ ${ }^{2}$ Tribhuvan University, Kathmandu, Nepal \\ ${ }^{3}$ King Abdullah University of Science and Technology (KAUST), Physical Sciences and Engineering Division, \\ Thuwal, Saudi Arabia \\ ${ }^{4}$ Centre for Climate Change Research, Indian Institute of Tropical Meteorology, Pune, India
}

\begin{abstract}
*lkumarap@hotmail.com
Abstract

In the present study, rainfall estimates from TRMM (Tropical Rainfall Measuring Mission) and GPM (Global Precipitation Mission) constellation of satellites are analyzed in the context of rainfall induced landslide occurrences over Western Ghats (WG) of India along with the daily gridded rainfall data developed by the India Meteorological Department (IMD) and ARWWeather Research and Forecasting (WRF) numerical model simulations. This study aims to analyze the pattern of changes in rain rate and total rainfall triggering the large landslides over WG in TMPA (product of TRMM) and IMERG (GPM product) rainfall data sets. As a case study, performance of IMERG V5 is assessed during Malin landslide which occurred on 30 July 2014 (initial GPM era). Results indicate that IMERG shows significant increase in rain rate (> 60mm/h in half-hourly data) during Malin landslide. Near real-time IMERG V5, underestimates the rain rate but increasing pattern of rain-rate are observed which is similar to that of final version. Spatial pattern of ARW-WRF rainfall output is also close to the satellite and IMD rainfall patterns. We propose that IMERG V5 can be used as an indicator to reliably depict the higher rainfall scenario over the sites that are vulnerable to rainfall induced landslide occurrence over the WG region.
\end{abstract}

Keywords: - GPM, TRMM, IMD gridded rainfall, rainfall induced landslides, Western Ghats 


\section{Introduction}

India is among the most affected countries with the highest percentage of landslide fatalities in the past few years (Froude and Petley, 2018). Rainfall- induced landslides account as a cause of major public concern as they claimed untold number of human lives and caused economic losses every year worldwide. Kirschbaum and Stanley (2018) reported that hazards like tropical cyclones, floods, fires, and volcanoes are studied and monitored by systems in space like satellite or airborne instruments operating in visible, infrared and /or microwave and / or regions of electromagnetic spectrum. However, landslide hazard monitoring lacks proper situational awareness at global and regional scale. Landslide Hazard Assessment for Situational Awareness (LHASA) model using rainfall data from the Global Precipitation Measurement (GPM) mission infers Western Ghats (WG), a populated mountainous range along the western coast of India, is one of the vulnerable landslide sights facing significant infrastructure damage and life loss due to rainfall-induced landslides. Steep westward slope coupled with intense rainfall (360 cm per annum) and other geological and climatological factors make WG susceptible to landslides (Basak and Narasimhaprasad, 1989).

Studies explored that heavy and prolonged rainfall events saturate the soil moisture which in turn cause the ground vulnerable to land sliding, thus they act as the frequent trigger of landslides around the world (Petley et al., 2005). In India, the occurrence of landslides is pronounced during the monsoon period (Southwest monsoon-June to September and Northeast monsoon-October to December) (NDMA, 2009). A review on rainfall thresholds of land slide occurrence revealed that $79.5 \%$ of the studies made use of the rain gauge network and remaining studies used a combination of rain gauge, radar and satellite rainfall data (Segoni et al., 2018). Utilization of satellite estimated rainfall products attained greater importance to study the landslides over the terrain region of WG, where the density of rain gauge is inadequate to 
assess the site-specific landslide occurrence. Compared with rain gauge data that normally requires considerable amount of time to quality check and collate, the celerity with satellite rainfall attracts the scientific and operational community. However, it is not to say that satellite rainfall estimates are without problems especially over mountains (Dinku et al., 2007). Although, in recent times, availability of passive microwave and space borne active precipitation radar along with Infrared techniques have revolutionized rainfall estimation and their characteristic study from space (Hou et al., 2008). TMPA/IMERG products are the promising multi-satellite precipitation products available at very high spatio-temporal resolutions. Brunetti et al., (2018) and Rossi et al., (2017) have used TRMM rainfall products along with other in-situ rainfall products to study the landslide threshold where they have reported empirical rainfall conditions associated with uncertainties in the regions of Italy. Globally numerous studies were carried out to study the rainfall induced landslides and reported the threshold rainfall conditions over their study regions (Ma et al., 2015; Peruccacci et al., 2017; Teja and Dikshit, 2019). To obtain the rainfall threshold for a region, a large number of landslide events needs to be considered and taken in to account. In the present study, we used three landslide events over WG region to report the satellite estimated rainfall data capability in examining the rainfall induced landslide occurrence as the main objective. As part of the analysis, we have also used the IMD gridded rainfall and WRF model simulated rainfall data to understand the ability of satellites in depicting reliable rainfall values during occurrences of landslides.

\section{Study area}

Western Ghats (WG) [Fig.1 (a)] cover complex topographical areas moving parallel to the western coast of India along Arabian Sea. The average elevation of the mountainous region of WG is about 1,100 meters and it is nearly 1,600 km long (Basak and Narasimhaprasad, 1989). The westward slope of this range is steeper whereas it is gentle towards the east. Because of the 
very old rock formations (older than Himalayas) coupled with intense rainfall, moist atmosphere, and other unfavorable geological and climatological factors, the WG mountainous range is unstable (Basak and Narasimhaprasad, 1989). The key structural features of WG and its geomorphic units have major role in the initiation of cataclysmic rainfall induced landslides towards windward slope of Western Ghats during southwest monsoon season. Series of small and large rainfall induced landslides are very common in every monsoon season in this region.

\section{Data and Methodology}

\subsection{Landslide information:}

In the present study, we have made use of widely investigated (Kirschbaum et al., 2015; Lin et al., 2017) Global Landslide Catalogue (GLC) developed by NASA to collect the information about landslide occurrences (https://data.nasa.gov/dataset/Global-Landslide-CatalogExport/dd9e-wu2v) over WG of India during 2007 to 2015. From the selected landslides over WG, rainfall induced large landslides are chosen and their location (latitude, longitude), size, time of occurrence is obtained.

Here, the following three landslides are considered: Malin landslide which occurred during the morning time of $30^{\text {th }}$ July 2014(event 1), land slide in Andheri (located in Mumbai, Maharashtra) during night time of $3^{\text {rd }}$ September 2009 (event 2) and the third at Ayanur (located in Karnakata) on $12^{\text {th }}$ Aug 2008 (event 3). These three landslide events in the present study are rainfall induced landslides, occurred at different locations of WG region, and created massive damage that lead to huge loss of property along with human life. Geographical location (longitude/latitude), elevation, etc. of the above mentioned events are listed in Table 1. 
Fig.1 shows the location of the three landslide events under study. Elevation around the landslide site is mapped by using CARTOSAT-1 Digital Elevation Model (DEM), which provides an elevation reference of the existing topographic conditions. The spatial resolution of the DEM data used here is 1 arc second.

\subsection{Rainfall data sets}

\subsubsection{Satellite based rainfall:}

Rainfall estimates from constellation of TRMM and GPM satellites products namely, TRMM Multi-satellite Precipitation Analysis (TMPA-3B42 V7) and Integrated Multi-satellitE Retrieval of GPM (IMERG) version 5 final and real-time (RT) products have been used. The TMPA consist of 3-hourly and daily rainfall estimates at $0.25^{\circ} \times 0.25^{\circ}$ spatial resolution covering the tropics whereas IMERG is available at much higher spatial and temporal resolution $\left(0.1^{\circ} \mathrm{X} \quad 0.1^{\circ}\right.$ latitude/longitude spatial resolution and $30 \mathrm{~min} /$ daily temporal resolution). These data sets are available at different run time as near real time or early multi-satellite product (available after 4 hr after observation time) and final satellite-gauge product for research purpose (available after two months after observation time). Details of the satellite datasets used in the present study can be found in Huffman et al., 2015, 2007; Thakur et al.,2018; Lakshmi Kumar et al., 2019). These data sets have proven as better substitutes of ground gauge measurements of rainfall over different regions of India (Prakash et al., 2015; Uma et al., 2013). Thakur et al. (2020) subjected the rainfall data sets of IMERG to different statistical tests and reported the good agreement of IMERG with the IMD rainfall data sets in India at different space and time scales. Our statistical analysis shows that IMERG has good agreement with IMD rainfall over the central Indian region except during extreme heavy rain events $(\geq 204.5 \mathrm{~mm})$. As far as the spatial pattern is concerned, it well performs over India in depicting the large-scale 
features of summer monsoon rainfall (such as higher rainfall zones over Western Ghats, northeast parts of India and lower rainfall regimes in northwest part of India and portions of south east India) but with different biases. Furthermore, we have examined the two data sets of IMERG, at $0.25^{\circ} \times 0.25^{\circ}$ and $0.1^{\circ} \times 0.1^{\circ}$, along with the IMD data at $0.25^{\circ} \times 0.25^{\circ}$ by subjecting them to probability distribution function (PDF) analysis. Our analysis shows that the PDFs of IMERG at $0.25^{\circ} \times 0.25^{\circ}$ (regridded data sets) and $0.1^{\circ} \times 0.1^{\circ}$ do not show any significant variations in shape and scale. Though satellites show some limitations in estimating the reliable rainfall amounts over terrain regions like WG, studies of Thakur et al.,(2019) proposed a new criterion where the satellite rainfall data sets can be considered more reliably. As per the criteria proposed by Thakur et al.,(2019) the chosen landslide dates show the moist static stability and wind at $200 \mathrm{mb}$ above the climatological mean values, which strengthens that the rainfall from satellite over these days can be taken into account more reliably.

\subsubsection{Ground based rainfall:}

As a benchmark, IMD4 gridded rainfall data sets of IMD are used in the present study. These gridded data sets have been developed by IMD based on the rainfall data collected from the wide number of rain gauges across India. The details of interpolation techniques and quality control metrics can be found in Pai et al. (2014). The spatial and temporal resolution of these data sets is $0.25^{\circ} \times 0.25^{\circ}$ and with daily time scale. The density of rain gauges along with the topography over India considered to develop these data sets is discussed in Thakur et al. (2019).

\subsubsection{WRF Simulated rainfall:}

Most of the global rainfall products and IMD4 gridded rainfall are available at relatively coarse resolution and it may not be sufficient to assess rainfall-induced landslides. Hence, with 
the paucity of high-resolution rainfall data sets, they need to be simulated. Therefore, regional meso- scale models like advanced research version of the Weather Research and Forecasting (WRF) model has been used to obtain rainfall information at finer grid resolution (Chawla et al., 2018). Modeling rainfall during rainfall induced landslides occurrence is an enduring challenge, as such heavy rainfall events rely on multi-scale atmospheric interactions, and the model set up. With this background, the WRF modeled rainfall information is executed in the present study to see the agreement among spatial rainfall pattern of satellite-estimated rainfall, IMD rainfall and simulated rainfall pattern on landslide day around the site of landslide occurrence by considering three representative test events that occurred over Western Ghats.

\subsubsection{Model setup:}

WRF model version 3.9 is used to simulate the rainfall during landslide events. It is a non-hydrostatic, numerical weather prediction model having many advance schemes and physics to simulate the weather. Additional details on WRF are available on WRF user webpage (http://www2.mmm.ucar.edu/wrf/users/). It makes use of lateral large-scale boundary condition and atmospheric forcing as initial condition. We have used the most common National Centers for Environmental Prediction (NCEP) global FiNaL (FNL) analysis dataset available at $0.25^{\circ} \mathrm{X}$ $0.25^{\circ}$ spatial resolution and 6 hour temporal resolution: 00:00, 06:00, 12:00 and 18:00 UTC as input. In the present study, we use WRF to visualize the concentric rainfall amounts over the sites of landslide events. We have used the standard schemes to retrieve the rainfall from WRF. For micro physics, -WSM 6 scheme, Cumulus-Physics - Grell -Freitas scheme (Grell and Freitas, 2014), PBL - 1 (Yonsei University Scheme) (Hong et al., 2006), Surface model - 5 layer thermal diffusion scheme, Radiation law physics - RRTMG shortwave and long wave 
scheme (Dudhia, 1989) have been used. WRF simulation of all the three events is made at spatial resolution of $9 \mathrm{~km}$ square grid.

\section{RESULT AND DISCUSSION}

At first, we have examined the 3-hourly rain rate patterns during the occurrence of the three landslides to understand the antecedent and subsequent pattern of rain rate obtained from the satellite products.

Fig. 2(a-c) shows the rainfall pattern of the three landslide events which occurred on $30^{\text {th }} \mathrm{Jul}$ 2014 (event 1), $3^{\text {rd }}$ Sep 2009 (event 2) and $12^{\text {th }}$ Aug 2008 (event 3) respectively. The rainfall data for these time series are obtained from the TMPA 3B42 V7 data sets with a spatial resolution of $0.25^{\circ} \times 0.25^{\circ}$ and a temporal resolution of 3 hours. A close observation of Fig. 2(a-c) reveals either an intense or continuous rainfall pattern at the time of landslide occurrences. Antecedent rainfall seem to have played a key role during these disastrous events. The rain rate for the event 1 reached approximately $25 \mathrm{~mm} / \mathrm{h}$ at the time of landslide occurrence. During events 2 and 3, the corresponding rain rates are $10 \mathrm{~mm} / \mathrm{h}$ and $12 \mathrm{~mm} / \mathrm{h}$ respectively. The TMPA rainfall for the event 1 differed from the rainfall pattern of events 2 and 3 . Therefore, it can be learnt that a continuous rainfall pattern triggered the landslide occurrence in event 1 while the other two are possibly the effects of sudden increase in rain rate.

This distinguishing rainfall pattern during the three landslide events needs to be studied in detail with the other geo-morphological conditions for a better understanding of the landslide occurrence. Here, our focus is to see how high quality satellite estimated rainfall data can complement the study of landslide occurrences from conventional methods. It is to be noted that the data set used for Fig. 2 is with a spatial resolution of $0.25^{\circ} \mathrm{X} 0.25^{\circ}$ and a temporal resolution 
of 3 hours. With the arrival of GPM core in 2014 (mainly with two frequency active radar) with 30 minutes temporal resolution and $0.1^{\circ} \times 0.1^{\circ}$ spatial resolution, an effective understanding on the rainfall pattern over the specific locations of the landslides can be possible. Among the three test landslide events, Malin landslide (event 1) falls in the period of GPM core era and hence we show from those data the rainfall pattern during the Malin landslide occurrence on the nearest hours of 30 July 2014.

Fig.3 Shows half-hourly variation of IMERG V5 final and early (real time) data for the afore mentioned event (i.e. event1).

Both final and early data sets of the IMERG V5 show a consistent pattern throughout event 1 period (29 July to 30 July 2014). However, there are some disparities among the magnitudes of the two rainfall data sets. Visual inspection of half- hourly data of the both data sets shows a gradual increase of rainfall that reached the peak value at the time of occurrence of the Malin landslide. Thereafter, the rainfall receded. This kind of pattern is not seen when we consider 3hourly TMPA products i.e. coarse temporal resolution of 3-hour. In addition, it is worth mentioning that at higher spatial resolutions, satellites are well capable to detect the atmospheric processes such as deep convection, which will lead to better estimation of rainfall (Thakur et al., 2019). Thus, GPM provides reliable estimates of rainfall due to its higher spatial resolution compared to that of TRMM, which have poorer spatial resolution than GPM.

In addition to temporal distribution of rainfall, the spatial extent of rains is important during the landslides, as the spatial rainfall pattern will alter the soil conditions. Gao et al., (2017) have shown significant correlation between spatial distribution of rainfall and landslide occurrence over Hong-Kong. In the present work, we have evaluated the spatial distribution of rainfall estimates from satellites during the above-mentioned events. We have attempted to 
evaluate the spatial pattern of rain rate around the $1^{\circ}$ square grid around the landslide area. The spatial pattern of rainfall distribution for the three landslide locations are shown in the Fig.4. The event 1 (Malin landslide) is surrounded by higher rainfall scenario compared to other two events. From this it is evident that the event 1 is more disastrous compared to the other the two events.

The accumulated rainfall, which is responsible for rainfall infiltration, continuous soil wetness and finally causing the slope failure leading to landslides. This been studied by several authors (Amit et al., 2017; Brunetti et al., 2018; Melillo et al., 2018) and is stressed that role of accumulated rainfall is one of the primary conditions for triggering the landslides. Here, we have also observed the quantitative pattern of five days accumulated daily rainfall over the grid where landslide took place from IMERG V5 (for event 1) and TMPA 3B42 (for event 2 and 3) as it happened before GPM era.

The accumulated rainfall patterns of the three events also show a steady increase of rainfall, which triggers the landslides. In the case of Malin landslide (event 1) IMERG V5 has shown 500 mm of accumulated rainfall for the 5 days whereas in the case of event 2 and event 3 , the rainfall accumulation of $100 \mathrm{~mm}$ and $200 \mathrm{~mm}$ respectively are observed by the TMPA 3B42 products.

Further, ground based IMD4, satellite based TMPA / IMERG and WRF simulated (9 $\mathrm{km} X 9 \mathrm{~km}$ grid resolution) spatial rainfall pattern are analyzed at their native spatial resolution to understand the disparities in the satellite rainfall products. For event 1 (Malin landslide) final and real time (RT) products of IMERG along with IMD4 and WRF simulated rainfall have been taken whereas, for event 2 and event 3, TMPA 3B42 final and real time (RT) products along with those of IMD4 and the WRF model daily spatial rainfall pattern are analyzed in $1^{\circ} \mathrm{X} 1^{\circ}$ latitude/longitude area centered around landslide sites (Fig. 6). 

whereas agreement between TMPA, model and IMD are found to be poorer. It is justified from this analysis that rainfall induced landslides can be monitored more effectively with IMERG and WRF simulated rainfall. As there is a dearth of conventional measurements over the mountainous regions, satellite high-resolution data sets along with ARW- WRF simulated rainfall data set may serve as the reliable option. Among available satellite rainfall products, IMERG V5 shows better variability in rain rate as it is available at half-hourly interval during Malin landslide than that of 3 hourly TMPA 3B42.

\section{Conclusion}

Utilization of satellite derived high-resolution rainfall data for monitoring the landslide occurrences attained a greater importance in the global context as the satellites provide the near real time rainfall data. Taking this into consideration, the present study aims to examine the high resolution satellite based rainfall data sets of IMERG during the rainfall induced landslide occurrences over Western Ghats. IMD gridded data sets and WRF model simulated rainfall data are also used to compare the satellite derived rainfall products in order to understand the efficiency of IMERG. Since the IMERG data is available during the Malin landslide occurrence, this has been compared with the other two landslide events to report the advantage of IMERG than TRMM. Our study indicates that IMERG is able to indicate the increased rain rate during the Malin landslide occurrence more reliably as the IMERG data is available with 30 minutes time interval and $0.1^{\circ} \times 0.1^{\circ}$ spatial resolution. Not only the rain rate, but also the rainfall distribution around the landslide event are better captured by IMERG which is revealed during the comparative analysis of IMERG with IMD and WRF simulated rainfall scenarios. Near real time IMERG does not vary much with the final run IMERG rainfall data which is advantageous for real time monitoring of landslides. However, more landslide events to be considered to 
confirm the IMERG performance over Western Ghats as the present study consider a few landslides.

\section{Declaration of competing interest}

The authors declare that they have no known competing interest.

\section{Acknowledgements}

Authors are thankful to the anonymous reviewers for their constructive comments that improved the quality of the article. The author Mr. Manoj Kumar Thakur is thankful to Silver Jubilee Scholarship Scheme-Govt. of India under which he is sponsored.

\section{References}

Amit, K., Asthana, A.K.L., Priyanka, R.S., Jayangondaperumal, R., Gupta, A.K., Bhakuni, S.S., 2017. Assessment of landslide hazards induced by extreme rainfall event in Jammu and Kashmir Himalaya, northwest India. Geomorphology. 284, (72-87). https://doi.org/10.1016/j.geomorph.2017.01.003

Basak, P., Narasimhaprasad, N.B., 1989. Recurring Landslides in the Western Ghats —an Environmental Hazard. Environ. Conserv.

$(16(2), 169-172$ https://doi.org/10.1017/S0376892900008961

Brunetti, M.T., Melillo, M., Peruccacci, S., Ciabatta, L., Brocca, L., 2018. How far are we from the use of satellite rainfall products in landslide forecasting? Remote Sens. Environ. 210, 65-75. https://doi.org/10.1016/j.rse.2018.03.016

Chawla, I., Osuri, K.K., Mujumdar, P.P., Niyogi, D., 2018. Assessment of the Weather Research and Forecasting (WRF) model for simulation of extreme rainfall events in the upper Ganga 
Basin. Hydrol. Earth Syst. Sci. 22, 1095-1117. https://doi.org/10.5194/hess-22-1095-2018

Dinku, T., Ceccato, P., Grover-Kopec, E., Lemma, M., Connor, S.J., Ropelewski, C.F., 2007. Validation of satellite rainfall products over East Africa's complex topography. Int. J. Remote Sens. 28, 1503-1526. https://doi.org/10.1080/01431160600954688

Dudhia, J., 1989. Numerical Study of Convection Observed during the Winter Monsoon Experiment Using a Mesoscale Two-Dimensional Model. J. Atmos. Sci. 46(20), 3077-3107. https://doi.org/10.1175/1520-0469(1989)046<3077:NSOCOD>2.0.CO;2

Froude, M.J., Petley, D.N., 2018. Global fatal landslide occurrence from 2004 to 2016. Nat. Hazards Earth Syst. Sci. 18, 2161-2181. https://doi.org/10.5194/nhess-18-2161-2018

Gao, L., Zhang, L., Lu, M., 2017. Characterizing the spatial variations and correlations of large rainstorms for landslide study. Hydrol. Earth Syst. Sci. 21, 4573-4589. https://doi.org/10.5194/hess-21-4573-2017

Grell, G.A., Freitas, S.R., 2014. A scale and aerosol aware stochastic convective parameterization for weather and air quality modeling. Atmos. Chem. Phys. 14(10), 52335250. https://doi.org/10.5194/acp-14-5233-2014

Hong, S.-Y., Noh, Y., Dudhia, J., 2006. A New Vertical Diffusion Package with an Explicit Treatment of Entrainment Processes. Mon. Weather Rev. 134(9), 2318-2341. https://doi.org/10.1175/MWR3199.1

Hou, A.Y., Skofronick-Jackson, G., Kummerow, C.D., Shepherd, J.M., 2008. Global precipitation measurement. Precip. Adv. Meas. Estim. Predict. 353, 131-169. https://doi.org/10.1007/978-3-540-77655-0_6

Huffman, G.J., Bolvin, D.T., Braithwaite, D., Hsu, K., Joyce, R., Kidd, C., Nelkin, E.J., Xie, P., 2015. NASA Global Precipitation Measurement (GPM) Integrated Multi-satellitE 
Retrievals for GPM (IMERG). Algorithm Theor. Basis Doc. Version 4.5 26.

Huffman, G.J., Bolvin, D.T., Nelkin, E.J., Wolff, D.B., Adler, R.F., Gu, G., Hong, Y., Bowman, K.P., Stocker, E.F., 2007. The TRMM Multisatellite Precipitation Analysis (TMPA): QuasiGlobal, Multiyear, Combined-Sensor Precipitation Estimates at Fine Scales. J. Hydrometeorol. 8, 38-55. https://doi.org/10.1175/JHM560.1

Kirschbaum, D., Stanley, T., 2018. Satellite-Based Assessment of Rainfall-Triggered Landslide Hazard for Situational Awareness. Earth's Futur. 6, 505-523. https://doi.org/10.1002/2017EF000715

Kirschbaum, D., Stanley, T., Zhou, Y., 2015. Spatial and temporal analysis of a global landslide catalog. Geomorphology. 249, 4-15. https://doi.org/10.1016/j.geomorph.2015.03.016

Lakshmi Kumar, T. V.,, Humberto Alves Barbosa*, M.K.T. and F.P.-T., 2019. Validation of Satellite (TMPA and IMERG) Rainfall Products with the IMD Gridded Data Sets over Monsoon Core Region of India. IntechOpen, pp. 0-12. https://doi.org/http://dx.doi.org/10.5772/intechopen.84999

Lin, L., Lin, Q., Wang, Y., 2017. Landslide susceptibility mapping on a global scale using the method of logistic regression. Nat. Hazards Earth Syst. Sci. 17, 1411-4424. https://doi.org/10.5194/nhess-17-1411-2017

Ma, T., Li, C., Lu, Z., Bao, Q., 2015. Rainfall intensity-duration thresholds for the initiation of landslides in Zhejiang Province, China. Geomorphology. 245, 193-206. https://doi.org/10.1016/j.geomorph.2015.05.016

Melillo, M., Brunetti, M.T., Peruccacci, S., Gariano, S.L., Roccati, A., Guzzetti, F., 2018. A tool for the automatic calculation of rainfall thresholds for landslide occurrence. Environ. Model. Softw. 105, 230-243. https://doi.org/10.1016/j.envsoft.2018.03.024 
NDMA, 2009. National Disaster Management Guidelines Management of Landslides and Snow Avalanches 1-190.

Pai, D.S., Sridhar, L., Rajeevan, M., Sreejith, O.P., Satbhai, N.S., Mukhopadhyay, B., 2014. Development of a new high spatial resolution $\left(0.25^{\circ} \times 0.25^{\circ}\right)$ long period (1901-2010) daily gridded rainfall data set over India and its comparison with existing data sets over the region. Mausam. 65(1), 1-18.

Peruccacci, S., Brunetti, M.T., Gariano, S.L., Melillo, M., Rossi, M., Guzzetti, F., 2017. Rainfall thresholds for possible landslide occurrence in Italy. Geomorphology. 290, 39-57. https://doi.org/10.1016/j.geomorph.2017.03.031

Petley, D.N., Dunning, S.A., Rosser, N.J., 2005. The analysis of global landslide risk through the creation of a database of worldwide landslide fatalities. in: Landslide Risk Management. 299-320.

Prakash, S., Mitra, A.K., Pai, D.S., 2015. Comparing two high-resolution gauge-adjusted multisatellite rainfall products over India for the southwest monsoon period. Meteorol. Appl. 22(3), 679-688. https://doi.org/10.1002/met.1502

Rossi, M., Luciani, S., Valigi, D., Kirschbaum, D., Brunetti, M.T., Peruccacci, S., Guzzetti, F., 2017. Statistical approaches for the definition of landslide rainfall thresholds and their uncertainty using rain gauge and satellite data. Geomorphology 285, 16-27. https://doi.org/10.1016/j.geomorph.2017.02.001

Sarvade, S.M., Sarvade, M.M., Khadatare, P.S., Kolekar, M.R., 2014. 30/7 Malin Landslide: a Case Study. Gepsid 691-698.

Segoni, S., Piciullo, L., Gariano, S.L., 2018. A review of the recent literature on rainfall thresholds for landslide occurrence.Landslides. 15(8), 1483-1501. 
https://doi.org/10.1007/s10346-018-0966-4

Teja, T.S., Dikshit, A., 2019. Determination of Rainfall Thresholds for Landslide Prediction Using an Algorithm-Based Approach: Case Study in the Darjeeling Himalayas, India. Geosciences. 9, 302. https://doi:10.3390/geosciences9070302.

Thakur, M.K, Lakshmi Kumar, T. V., Dwivedi, S., Narayanan, M. S., 2018. On the rainfall asymmetry and distribution in tropical cyclones over Bay of Bengal using TMPA and GPM rainfall products. Nat. Hazards. 94(2), 819-832. https://doi.org/10.1007/s11069-018-3426-5(

Thakur, M.K., Lakshmi Kumar, T. V., Koteswara Rao, K., Barbosa, H., Rao, V.B., 2019. A new perspective in understanding rainfall from satellites over a complex topographic region of India. Sci. Rep. 9, 1-10. https://doi.org/10.1038/s41598-019-52075-y

Thakur, M.K., Lakshmi Kumar, T. V., Koteswara Rao, K., Barbosa, H., Narayanan,M.S., 2020. Analytical study of the performance of the IMERG over the Indian landmass. Meteorol. Appl. DOI: $10.1002 / m e t .1908$

Uma, R., Lakshmi Kumar, T. V., Narayanan, M.S., Rajeevan, M., Bhate, J., Kumar, K.N., 2013. Large scale features and assessment of spatial scale correspondence between TMPA and IMD rainfall datasets over Indian landmass. J. Earth Syst. Sci. 122, 573-588. https://doi.org/10.1007/s12040-013-0312-0 


\section{List of figure illustrations:}

Fig. 1(a). Distribution of rain gauges over Western Ghats (Thakur et al, 2019) along with the site specific locations of test landslide occurrences (solid dotted in red color with numbering and (b) Elevation map of the test landslides events

Fig. 2. TMPA 3B42 V7 3 hourly antecedent and subsequent rain rate for (a) event 1 (30 JUL 2014, Malin), (b) event 2 (3 SEP 2009, Andheri) and (c) event 3 (12 AUG 2008, Ayanur) rainfall induced landslide. (D0: landslide day, D-1: one day before landslide, D+1: one day after landslide)

Fig.3. Half-hourly IMERG Final and Early rain rate before and after Malin landslide occurrence i.e from $1330 \mathrm{hrs}$ IST of $29^{\text {th }}$ July to $1330 \mathrm{hrs}$ IST of $30^{\text {th }}$ July 2014.

Fig. 4. Spatial distribution of rain rate $(\mathrm{mm} / \mathrm{h})$ from TMPA $3 B 42 \mathrm{V7}$ for event 1 (Malin), 2 (Andheri) and 3 (Ayanur) (Red * denotes landslide sight) around the landslide occurrence location

Fig. 5. Five days satellite based accumulated rainfall over landslide sight for (a) event 1 (Malin), (b) event 2 (Andheri) and (c) event3 (Ayanur) (D0: landslide day, D-1: one day before landslide, D-2: two day before landslide: D-3: three day before landslide: D-4: four day before landslide)

Fig. 6. Daily rainfall (mm) estimate from (a) IMD, (b) IMERG/ TMPA, (c) IMERG-RT/TMPART and (d) WRF model for event 1(Malin landslide), event 2 (Andheri), and event 3 (Ayanur) over WG of India respectively [* denotes landslide location] 
Fig. 1

(a)

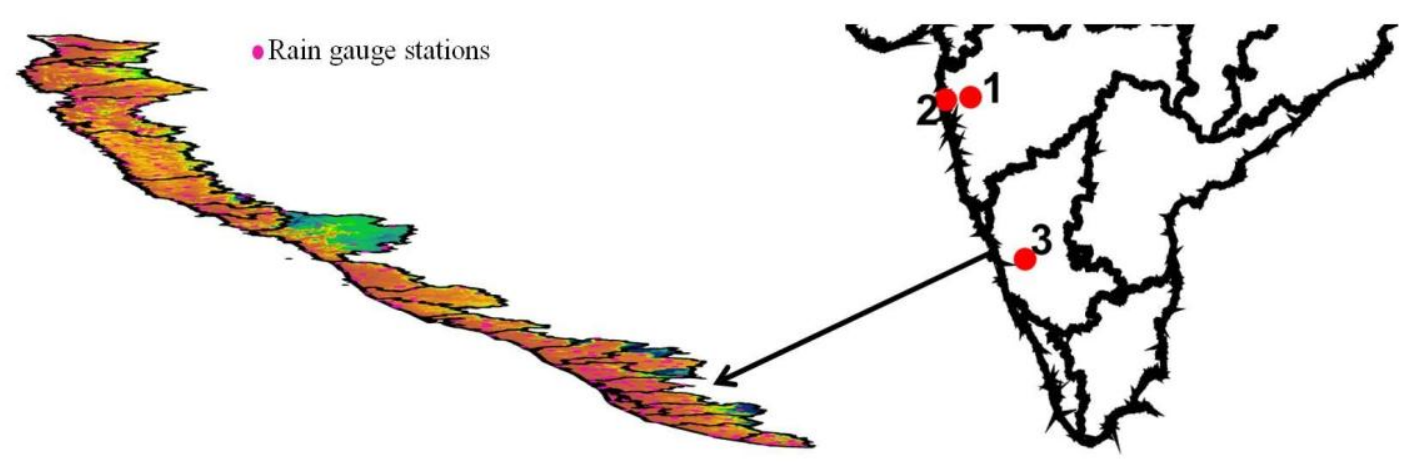

(b)
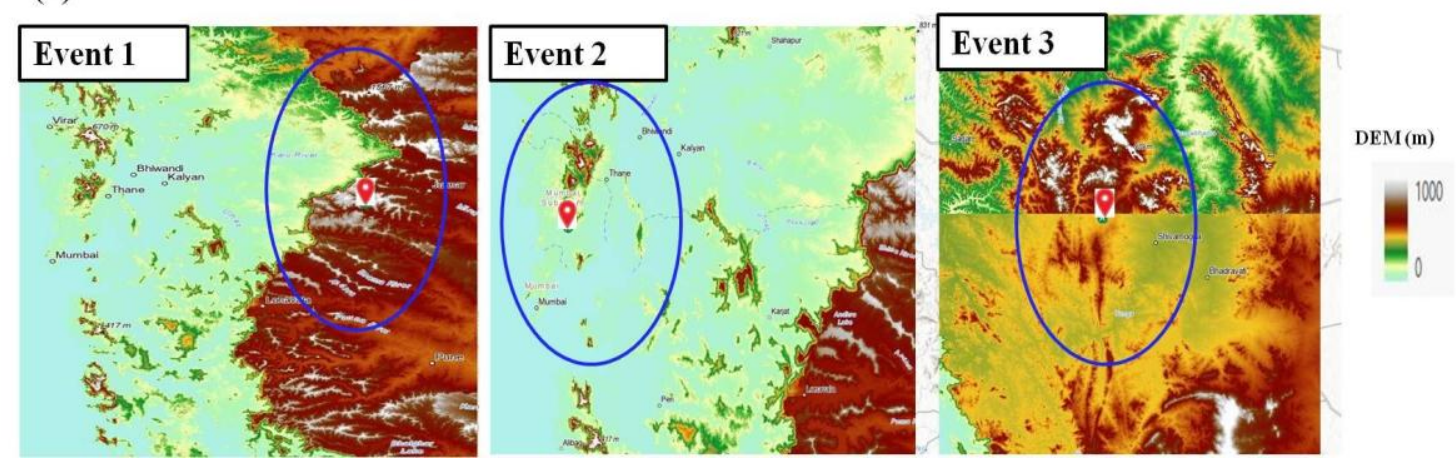
Fig. 2

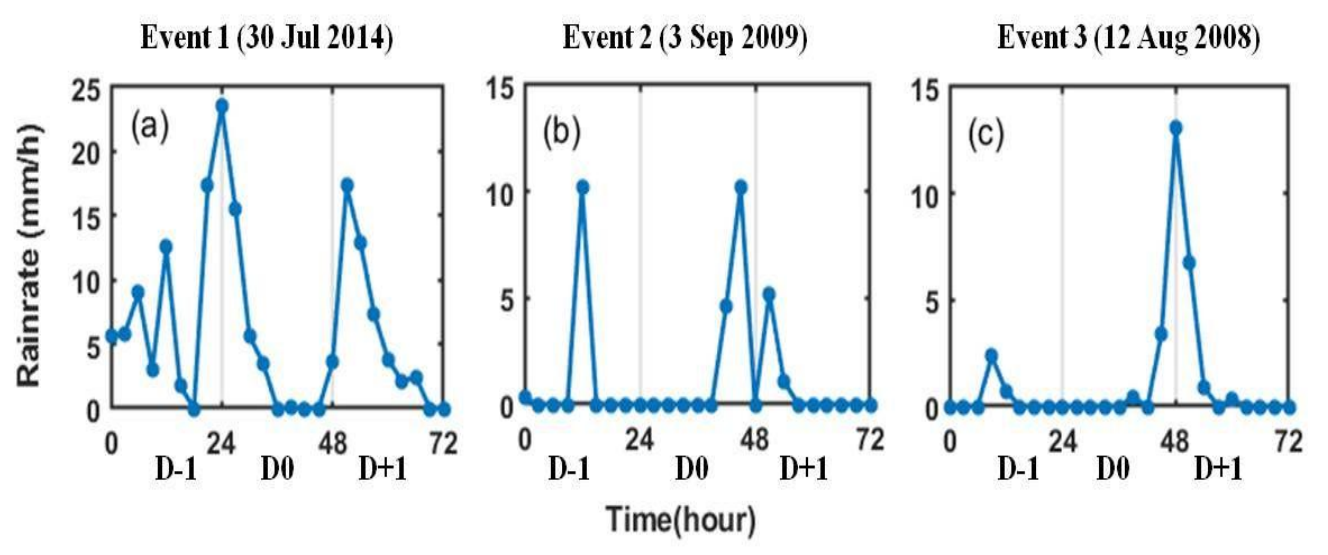

25

26

27

28

29

30

31

32

33

34

35

36

37

38

39

40

41

42

43

44

45

46

47

48

49

50

51

52

53

54

55

56

57

58

59

60

61

62

63 
Fig. 3

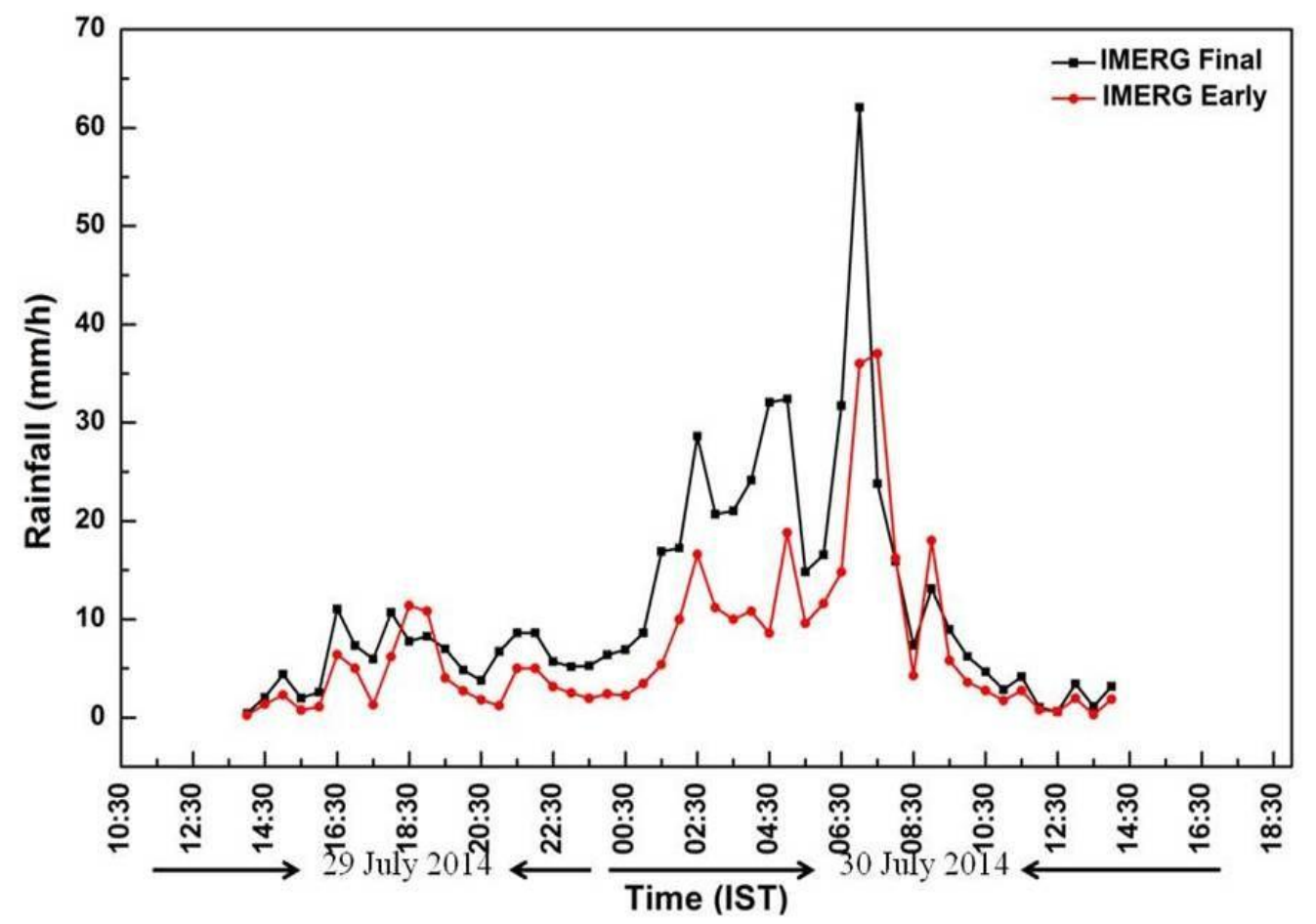


Fig.4
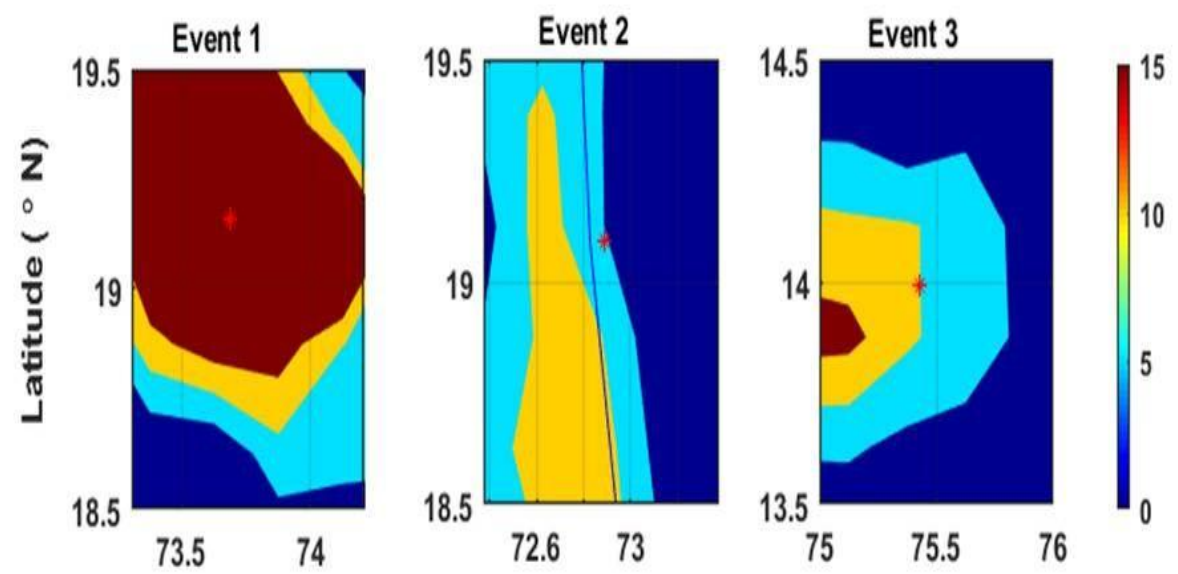

28

29

30

Longitude $\left({ }^{\circ} \mathrm{E}\right)$

32

33

34

35

36

37

38

39

40

41

42

43

44

45

46

47

48

49

50

51

52

53

54

55

56

57

58

59

60

61

62 
Fig.5

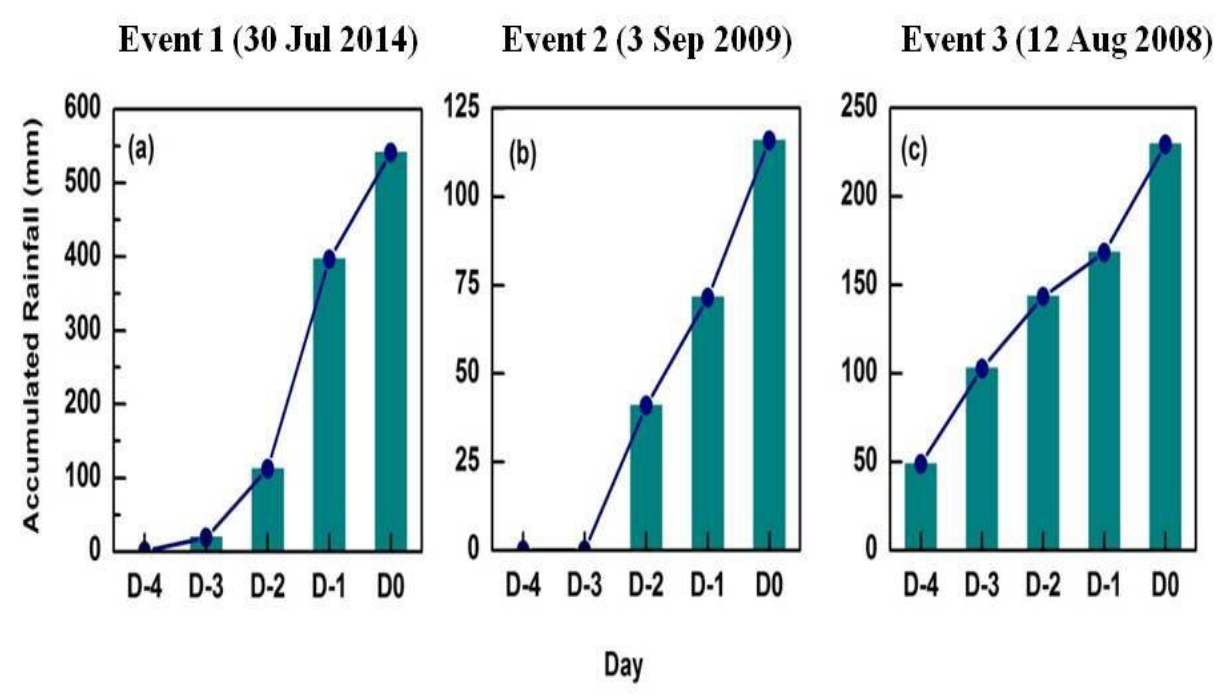

28

29

30

31

32

33

34

35

36

37

38

39

40

41

42

43

44

45

46

47

48

49

50

51

52

53

54

55

56

57

58

59

60

61

62

63 
Fig.6
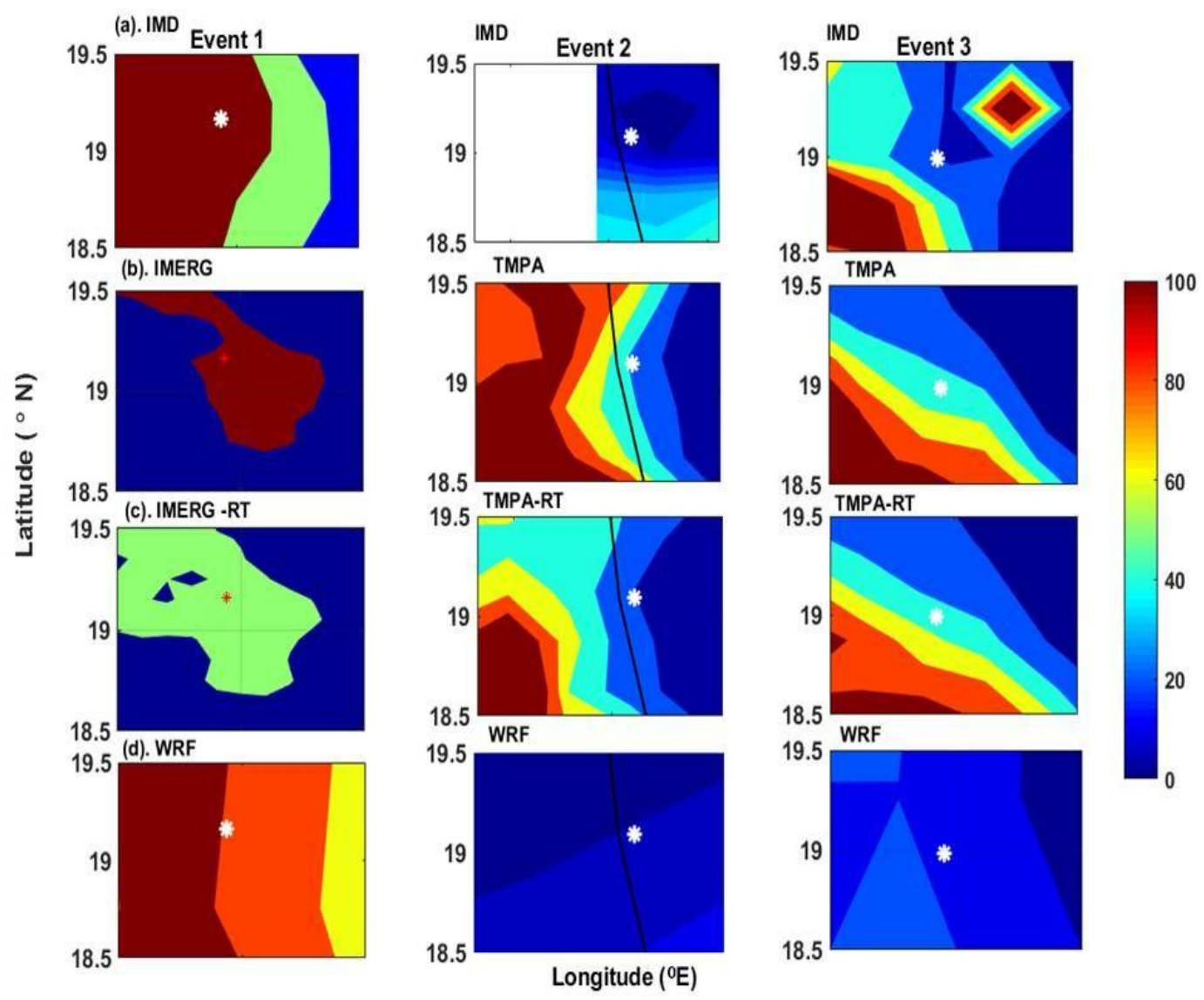


\section{List of table illustration}

Table. 1 Large landslide sights over WG of India

Table. 1

\begin{tabular}{|c|c|c|c|c|c|c|c|}
\hline $\begin{array}{c}\text { Date of } \\
\text { landslide }\end{array}$ & \multicolumn{1}{|c|}{ Lat(N) } & Lon(E) & Height(m) & TMPA(mm) & $\begin{array}{c}\text { Landslide } \\
\text { type }\end{array}$ & Trigger & $\begin{array}{c}\text { Time } \\
\text { UTC }\end{array}$ \\
\hline 12-Aug-08\# & 13.99 & 75.43 & 691 & 61.04 & Large & Downpour & $23: 00$ \\
\hline 3-Sep-09\# ${ }^{2}$ & 19.09 & 72.89 & 20 & 44.41 & Large & Downpour & $23: 30$ \\
\hline 30-Jul-14\# & 19.16 & 73.69 & 831 & 84.81 & Large & $\begin{array}{c}\text { Continuous } \\
\text { rain }\end{array}$ & $\begin{array}{c}\text { Morning } \\
\text { in } \\
\text { India* }\end{array}$ \\
\hline
\end{tabular}

(* reported by local people (Sarvade et al., 2014))

(source: https://data.nasa.gov/dataset/Global-Landslide-Catalog-Export/dd9e-wu2v). 